\title{
Integrated Semiconductor Laser Optical Phase Lock Loops
}

\author{
Katarzyna Balakier, Member, IEEE, Lalitha Ponnampalam, Member, IEEE, Martyn J. Fice, Member, IEEE, \\ Cyril C. Renaud, Member, IEEE, and Alwyn J. Seeds, Fellow, IEEE
}

(Invited Paper)

\begin{abstract}
An Optical Phase Lock Loop (OPLL) is a feedback control system that allows the phase stabilization of a laser to a reference laser with absolute but adjustable frequency offset. Such phase and frequency locked optical oscillators are of great interest for sensing, spectroscopy, and optical communication applications, where coherent detection offers advantages of higher sensitivity and spectral efficiency than can be achieved with direct detection. As explained in this paper, the fundamental difficulty in realising an OPLL is related to the limitations on loop bandwidth and propagation delay as a function of laser linewidth. In particular, the relatively wide linewidth of semiconductor lasers requires short delay, which can only be achieved through shortening of the feedback path, which is greatly facilitated through photonic integration. This paper reviews the advances in the development of semiconductor laser-based OPLLs and describes how improvements in performance have been enabled by improvements in photonic integration technology. We also describe the first OPLL created using foundry fabricated photonic integrated circuits and off-the-shelf electronic components. Stable locking has been achieved for offset frequencies between 4 and $12 \mathrm{GHz}$ with a heterodyne phase noise below $-100 \mathrm{dBc} / \mathrm{Hz}$ at $10 \mathrm{kHz}$ offset. This is the highest performance yet reported for a monolithically integrated OPLL and demonstrates the attractiveness of the foundry fabrication approach.
\end{abstract}

Index Terms-Optical phase locked loops, photonic integrated circuits, semiconductor laser, microwave photonics.

\section{INTRODUCTION}

$\mathbf{R}$ ESEARCH on optical phase lock loops started at an early stage of laser development when the use of lasers for optical communication applications began to be considered [1], [2]. Subsequent development of semiconductor lasers created demand for solutions to control the large free-running linewidth $(0.1$ to $50 \mathrm{MHz})$ of semiconductor diode lasers. The broad linewidth coupled with strong temperature and current

Manuscript received April 5, 2017; revised May 16, 2017; accepted May 18, 2017. This work was supported by the Engineering and Physical Sciences Research Council through COTS Project (EP/J017671/1) and European Commission Seventh Framework Programme (FP7-ICT) through IPHOBACNG (619870) and PARADIGM (257210) Projects. (Corresponding author: Katarzyna Balakier.)

The authors are with the Department of Electronic and Electrical Engineering, University College London, London, WC1E 7JE, U.K. (e-mail: k.balakier@ ucl.ac.uk; 1.ponnampalam@ucl.ac.uk; m.fice@ucl.ac.uk; c.renaud@ucl.ac.uk; a.seeds@ucl.ac.uk).

Color versions of one or more of the figures in this paper are available online at http://ieeexplore.ieee.org.

Digital Object Identifier 10.1109/JSTQE.2017.2711581 dependence of the emission frequency (typically $10 \mathrm{GHz} / \mathrm{K}$ and $1 \mathrm{GHz} / \mathrm{mA}$, respectively) required the implementation of special control techniques to stabilise the laser emission frequency and reduce the phase noise, which can reduce the receiver sensitivity of the system [3].

Phase stabilisation of an independent laser source can be achieved through a number of locking techniques that allow the relative phase difference between two lasers to be minimised. These are optical injection-locking (OIL), optical phase lock loop (OPLL), and a combination of these two techniques - optical injection phase-lock loop (OIPLL). OIL has been used in numerous applications including generating frequencies above $100 \mathrm{GHz}$ by injection locking to spectral lines from an optical comb [4]-[6]. However, the application of this technique is restricted by its homodyne nature and by a small locking range typically up to a few hundred $\mathrm{MHz}$ - thus it is necessary to control the laser temperature with milli-Kelvin precision [7]. This latter requirement is overcome in the OIPLL technique, in which wideband phase noise is suppressed, thanks to the injectionlocking mechanism, while the laser frequency drift and closeto-carrier phase noise are controlled through a phase-lock loop path. Systems based on OIPLL have been investigated for coherent receivers [8], satellite to ground communication [9], and high frequency signal synthesis [10]. However, in applications where a frequency offset between the optical reference source and the controlled (slave) laser is required, the OPLL technique offers a simpler system implementation in which the offset is exactly equal to a supplied microwave reference. A single mode laser is usually used as the optical reference tone, however a sideband resulting from a modulated laser or a line from an optical frequency comb can also be used as the reference tone for the OPLL. OPLLs have proven advantageous in numerous applications, including coherent optical communication systems [11], [12], high-purity mm-wave and $\mathrm{THz}$ signal generation [13] [16], coherent optical signal power combining [17], microwave photonics [18], [19], coherent terahertz photonics [20], precise measurements such as spectroscopy [21], [22], and astronomy [23], [24]. Some of the OPLLs were developed with very specific functionality such as a Costas loop based on an homodyne OPLL for coherent optical detection [25]. Others have been generic designs, addressing a wider range of applications [26].

The heterodyne OPLL configuration (see Fig. 1) allows the slave laser to be phase synchronised to the master laser (or 


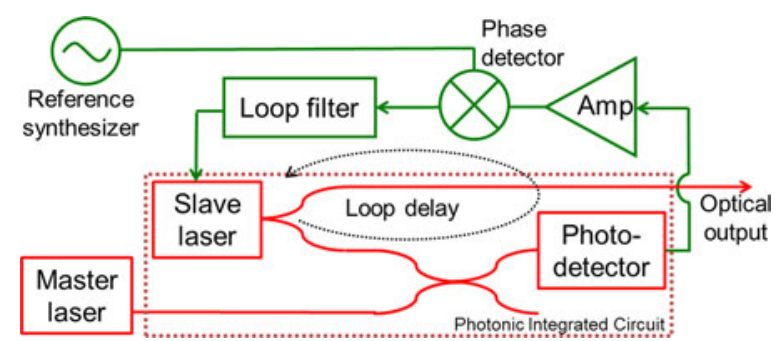

Fig. 1. Heterodyne OPLL schematic block diagram (red and green lines are optical end electrical paths, respectively).

reference optical tone) with variable frequency offset defined by the microwave reference. Both lasers are photomixed on the photodiode and the generated heterodyne is compared with a microwave reference frequency in the phase detector, resulting in a baseband phase error signal fed-back through the loop filter to the slave laser to tune it to track changes in the master laser phase. The OPLL can be challenging to realise in practice due to the required short phase-error propagation time within the loop. Extensive phase variation between broad-linewidth lasers can be controlled only within the bandwidth of the loop, hence the necessity for broad loop bandwidth. At the same time, the stability of the loop must be preserved in the presence of the delay. Therefore, the delay presents a fundamental limitation on the loop bandwidth.

Previous analytical studies and experimental demonstrations [27]-[29] showed that in order to phase stabilise two lasers with summed linewidth of a few $\mathrm{MHz}$, a loop with a few nanoseconds delay is required, which can be achieved only through integration of loop components, as one metre of optical fibre contributes approximately 5 ns delay. The first OPLL based on semiconductor lasers used micro-optics components to tackle the delay [17]. The present paper discusses how recent progress in photonic integration has enabled the development of OPLLs with optical path delay reduced to tens of picoseconds and total delay to a few nanoseconds or less.

In this paper we present a short introduction to the OPLL operation principle, its key characteristics and the most important parameters that need to be considered during the OPLL design process. This is done to provide background for discussion on the performance of several OPLL examples. Moreover, we describe the OPLL design challenges, which originate from the firm relationship between laser linewidth, loop delay, loop bandwidth and optimised gain.

We then provide an extensive overview of semiconductor laser-based OPLL systems developed over the years, with a particular focus on the effect the improvements in photonic integration have had on the progress in their development.

Finally, we present, for the first time, an OPLL realised using a generic foundry fabrication process and off-the-shelf microwave SMA-connectorised components. This novel OPLL is based on a tuneable Distributed Bragg Reflector (DBR) laser, which can be phase stabilised to the reference laser with a frequency offset in the range $4 \mathrm{GHz}$ to $12 \mathrm{GHz}$. The generated heterodyne phase noise is less than $-100 \mathrm{dBc} / \mathrm{Hz}$ at $10 \mathrm{kHz}$ offset from carrier for a separation of $8 \mathrm{GHz}$ between the lasers. Despite its simple realisation, the performance of this OPLL is comparable to systems developed previously using bespoke fabrication processes.

\section{OPERATION PRINCIPLE}

The heterodyne OPLL is a negative feedback control system where the phase of a current-controlled optical source the slave laser (SL) - is synchronised to that of an incoming optical reference signal-the master laser (ML), but with the addition of a frequency offset between SL and ML that is defined by an external reference synthesiser. The offset can be any frequency, although in practice it is limited by the bandwidth of the photodiode (PD) or RF electronic components. A schematic representation of the heterodyne OPLL is shown in Fig. 1.

The heterodyne OPLL operation can be explained as follows: due to the incident ML and SL optical fields on the photodiode, a photocurrent is generated and contains a component at a frequency corresponding to the difference between the frequencies of the two lasers polarised in the same direction. The photocurrent generated at the photodiode output can be described as:

$$
\begin{aligned}
i_{p d}= & R\left(P_{S L}+P_{M L}\right) \\
& +2 \mathrm{R} \sqrt{P_{S L} P_{M L}} \sin \left[\left(\omega_{S L}-\omega_{M L}\right) t+\varphi_{S L}-\varphi_{M L}\right]
\end{aligned}
$$

where: $R$ is the photodiode responsivity; $\mathrm{P}_{\mathrm{SL}}$ and $\mathrm{P}_{\mathrm{ML}}$ are the incident optical powers of the SL and ML; $\omega_{\mathrm{SL}}, \omega_{\mathrm{ML}}$ represent the angular frequency of the SL and ML; and $\varphi_{\mathrm{SL}}$ and $\varphi_{\mathrm{ML}}$ are the absolute phase of the SL and ML.

The photodiode is followed by a phase detector, which compares the heterodyne signal generated by the PD with an external RF frequency reference signal. When the frequencies of the heterodyne and reference signals are equal, a baseband error signal proportional to the phase difference between the two lasers is produced. The generated error signal is filtered by a low-pass loop filter and used to modulate the frequency of the SL. Extensive theoretical analysis and fuller description of the OPLL are available in previous works [27], [28]. It could be, however, restated that the effect of the loop propagation time delay and the impulse responses of all the loop components will have an effect on the error signal, which is fed into the SL and which can be expressed as follows:

$$
\begin{aligned}
i_{e}= & k_{L F} k_{m i x} k_{p d} k_{a m p} \\
& \sin \left[\left(\omega_{R F}-\omega_{S L}+\omega_{M L}\right) t+\varphi_{R F}-\varphi_{S L}+\varphi_{M L}\right] \\
& * h_{L F} * h_{m i x} * h_{a m p} * \delta\left(t-T_{d}\right)
\end{aligned}
$$

where: $k_{L F}$ is loop filter gain; $k_{p d}$ is photodetector gain $\left(2 \mathrm{R} \sqrt{P_{S L} P_{M L}}\right) ; k_{m i x}$ is phase detector conversion efficiency; $k_{a m p}$ is amplifier gain; $\omega_{R F}, \varphi_{R F}$ are the reference signal angular frequency and phase; $h_{L F}, h_{m i x}$ and $h_{a m p}$ are loop filter, mixer and amplifier impulse responses respectively; and $\delta\left(t-T_{d}\right)$ is the Dirac delta function of time delay $\left(T_{d}\right)$ in the loop.

The slave laser transfer function can be represented as follows:

$$
\frac{d \phi_{S L}}{d t}=k_{S L} i_{e} * h_{S L}
$$


where $k_{S L}\left[\frac{\mathrm{rad}}{\mathrm{sec}} / \mathrm{mA}\right]$ and $h_{S L}$ represent slave laser frequency modulation sensitivity and impulse response.

To simplify calculations, the loop components (such as the mixer, amplifier, photodetector, transmission lines, wirebonds and other interconnections) are considered to have uniform frequency response over the range of operation. Thus, the equations (2) and (3) are merged into:

$$
\frac{d \phi_{S L}}{d t}=K \varphi_{\mathrm{error}} * h_{L F} * h_{S L} * \delta\left(t-T_{d}\right)
$$

where $\varphi_{\text {error }}=\varphi_{R F}-\varphi_{S L}+\varphi_{M L}$ represents the relative phase difference between the SL and ML, which is assumed to be small, so $\sin \left(\varphi_{\text {error }}\right) \approx \varphi_{\text {error }}$. The open loop gain in the loop is described as:

$$
K=k_{L F} k_{m i x} k_{p d} k_{a m p} k_{S L}
$$

Loop gain $(K)$ has a primary effect on OPLL bandwidth and residual phase noise level. More detailed analyses of the feedback loop theory, including loop transfer functions, lock acquisition mechanisms, lock-in and hold-in range, can be found in [28], [30], [31].

One of the main characteristics of the OPLL is that it attempts to maintain a constant phase difference between the signals $\Delta=\varphi_{R F-} \varphi_{S L}+\varphi_{M L},(\Delta$ does not have to be zero) even if the frequency of the incoming signal $\left(\omega_{\mathrm{ML}}\right)$ varies over time. Assuming that the OPLL is in the locked condition and that the phase $\left(\varphi_{\mathrm{ML}}\right)$ of the incoming signal increases slightly, the phase difference between the SL and ML signals will begin to increase in time. As a result, the error signal generated by the loop changes and, in consequence, tunes the SL, whose output phase $\left(\varphi_{\mathrm{SL}}\right)$ increases until it matches the change in ML phase $\left(\varphi_{\mathrm{ML}}\right)$.

The same principles apply in homodyne OPLLs, the only difference being the absence of the mixer and reference synthesiser. In this system, phase error is detected by the photodiode. The locked condition is defined when the frequency between the two lasers is equal $\left(\omega_{\mathrm{SL}}=\omega_{\mathrm{ML}}\right)$ and the phase difference is fixed.

\section{A. Loop Order and Type}

OPLLs are generally classified according to the loop order and type, which depend on the type of the loop filter used. The order is determined by the order of the polynomial in the denominator of the loop transfer function. The type is the number of perfect integrations within the loop [31], [30]. All OPLLs are at least type 1, as the SL performs as an integrator because of its frequency tuning mechanism.

The purpose of the loop filter is to define the dynamics of the loop and preserve the stability by passing the DC and lowfrequency portions of the error signal while attenuating highfrequency components, including spurious mixing products.

To ensure wide tracking capabilities, hence increased temperature stability of the system and improved phase noise suppression at lower frequency offsets from the carrier, an active integrating loop is required [30]. By using an integrating loop filter, a type 2 loop may be realised. However, including an operational amplifier in the feedback loop can introduce excessive

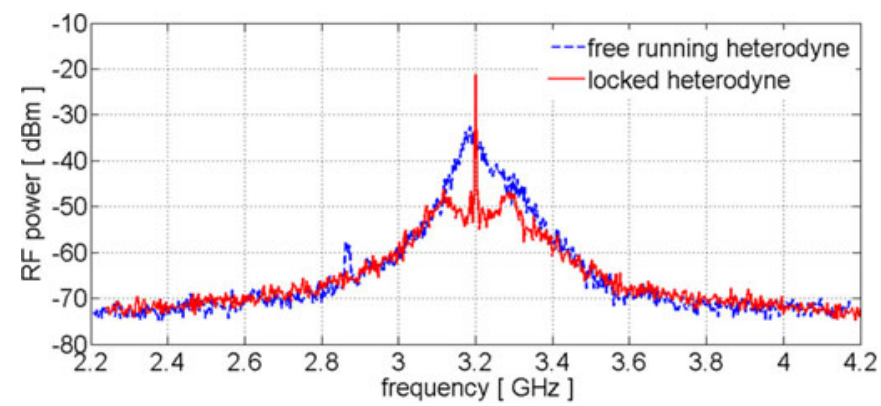

Fig. 2. Spectrum of unlocked and locked signals at an offset of $3.2 \mathrm{GHz}$ obtained by the OPLL described in [32]. RBW $=3 \mathrm{MHz}$.

delay. This can be reduced by implementation of a filter consisting of two separated paths: a high-speed proportional path and a slower integral path. The former offers a short propagation delay and better tracking of fast changes. The integral path tracks larger frequency changes, such as those caused by laser thermal drift [13].

\section{B. OPLL Performance}

The linewidth, together with wavelength fluctuations (lowfrequency drift) of the two lasers can be well observed in the electrical domain when the two lasers are heterodyned on a PD. In the same way, the improved spectral purity of the heterodyne signal can be observed when the OPLL is in operation. Fig. 2 shows an example of the measured electrical spectra of free-running and phase-controlled heterodyne signals from two lasers separated by $3.2 \mathrm{GHz}$. The total power of both signals remains unchanged, however the spectral distribution shows a large reduction in linewidth and increase in spectral power density at the beat frequency.

The peaks arising on either side of the phase-locked signal in Fig. 2 are the indicators of the loop bandwidth, which is the maximum frequency at which the phase of the SL can be controlled, so that the phase-error between the ML and SL is reduced. At higher frequencies, outside the loop bandwidth, the phase noise of the locked signal is the same as that of the freerunning heterodyne signal. The loop bandwidth is defined by the loop gain, loop filter, loop delay and frequency response of the components. In fact, semiconductor laser characteristics can impose restrictions on loop bandwidth; there can be a peak related to relaxation oscillation in FM response, or a phase reversal in the FM response, which is typical of conventional single-section DFB lasers and occurs at frequencies between 0.1 and $10 \mathrm{MHz}$ [33]. The dip in the laser FM response can be however reduced in the laser design process [34].

The spectrum of the heterodyne electrical signal contains a measurable residual phase noise that can be used as a precise metric to evaluate the quality of phase locking. The spectral purity of the heterodyne signal, and therefore loop performance, can be evaluated, based on phase noise power spectral density (PSD) or by the phase-error variance [31]. The former can be measured using a spectrum analyser or a dedicated phase noise measurement instrument [35]. The latter can be obtained by integrating the phase noise PSD over a specified frequency range. 
The phase-error variance is extensively used to evaluate the quality of various oscillators as it quantifies the total amount of residual phase noise [36], making it a useful parameter to compare the performance of different locking techniques. A variance of $0.03 \mathrm{rad}^{2}$, measured over the offset frequency range from $1 \mathrm{kHz}$ to $1 \mathrm{GHz}$, is often used as a target value as it corresponds to a phase-error standard deviation of $10^{\circ}$. However, it is not an ideal parameter for assessing OPLL performance due to the peak that is often present near roll-off in phase noise PSD of the OPLL-controlled heterodyne signal. The presence of this peak at higher offset frequencies from the carrier increases the variance value and consequently causes under-estimation of the OPLL's ability to suppress the phase noise at frequencies closer to the carrier.

\section{OPLL DESIGN AND CHARACTERISTIC PARAMETERS}

The OPLL is used as a building block in various system applications. Nevertheless, an OPLL can be considered a rather complex sub-system on its own. Design principles and parameters are known from phase stabilisation techniques used in electronic systems [31]. However, a fundamental difference between the optical and electronic phase lock loop (PLL) is the short loop delay required in an OPLL which is critical in determining the loop stability. This is directly linked to the nature of the voltage/current controlled oscillator whose phase noise needs to be controlled. The short cavity, quantum shot noise and other quantum processes result in the MHz-range linewidth of semiconductor lasers [37], [38]. For comparison, the linewidth of the voltage-controlled oscillator in an electronic PLL rarely exceeds tens of Hz. This enhanced linewidth of lasers creates considerable challenges in OPLL design, requiring a particularly large loop bandwidth and short loop delay.

A semiconductor laser intended for use as the SL must have good static spectral properties such as wavelength tuneability and a narrow linewidth. Moreover, the FM characteristic, including the tuning sensitivity, flatness and bandwidth of the FM response of the laser should also be well characterised to assess if the laser is suitable for use in the OPLL. The laser phase section tuning sensitivity and FM response are also of great importance as they are factors in the open loop gain, as seen in equation (5).

\section{A. Propagation Delay and Laser Linewidth Trade-Off}

Many OPLL systems have been analysed, assuming a negligible loop propagation delay time, which is acceptable if the loop is implemented with lasers with $\mathrm{kHz}$-range linewidth [14], [39] or if line-narrowing techniques are used [40], [41]. Nevertheless, propagation delay is present in all types of feedback systems, and is particularly relevant in the broadbandwidth loops required to control the phase of wider linewidth lasers. Consequently, as the transit time of the error signal around the loop becomes important, it must be considered in the loop design and kept very small, being less than a fraction of the inverse of loop bandwidth [28], [27]. To ensure loop stability and avoid performance degradation, a compromise between laser linewidth, loop bandwidth and loop propagation delay must be found.

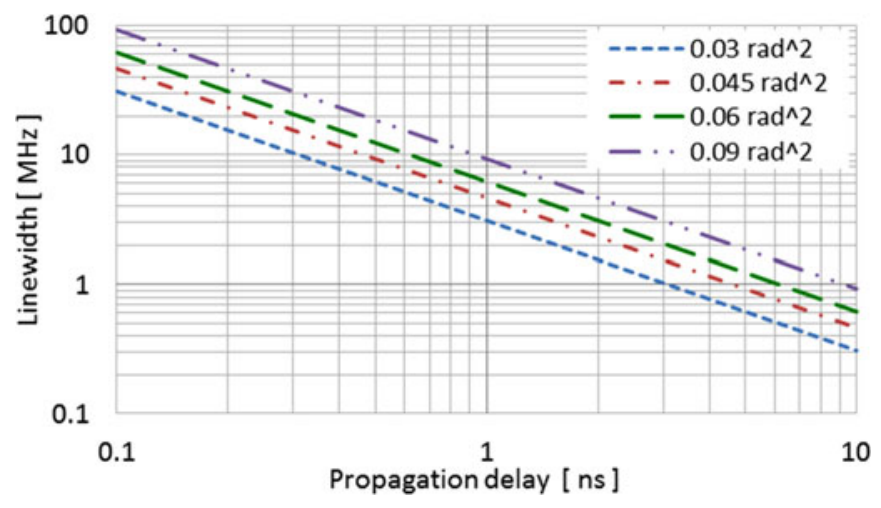

Fig. 3. Relationship between the summed linewidth of master and slave laser and delay in the loop with optimised gain, for different phase-error variances.

To quantify the delay requirements, the maximum tolerated linewidth for a given target phase error variance can be calculated as a function of loop delay [27], [42]. The relationship between phase-error propagation delay and the sum of the lasers' linewidth for a first-order type 1 loop with optimised gain is illustrated in Fig. 3 for phase-error variance ranging between $0.03 \mathrm{rad}^{2}$ and $0.09 \mathrm{rad}^{2}$, which corresponds to a phase-error standard deviation between $10^{\circ}$ and $17^{\circ}$. The lasers were assumed to have Lorentzian power spectra, and the phase error variance was obtained by integrating over frequencies from $1 \mathrm{kHz}$ to $1 \mathrm{GHz}$.

Fig. 3 indicates that, if $0.03 \mathrm{rad}^{2}$ variance is set as a target, a loop with 1 ns delay should successfully control the phase of a laser with linewidth of less than $3 \mathrm{MHz}$ (based on the assumption that an external-cavity laser with much narrower linewidth is used as ML). However, if the variance target is relaxed to 0.06 $\mathrm{rad}^{2}$, which corresponds to an average time between cycle slips of approximately 1 day [31], the same laser could be stabilised by the loop with 2 ns delay.

For comparison, 1 ns propagation delay corresponds to $300 \mathrm{~mm}$ of free-space path length or $200 \mathrm{~mm}$ of optical fibre. This highlights the importance of integration as using discrete diode lasers and optical fibres to build an OPLL with semiconductor lasers would be rather challenging.

\section{EARLY WORK}

The first optical phase lock loop was demonstrated for narrow linewidth gas lasers at an early stage of laser development [1], [2]. These first homodyne approaches faced technological difficulties due to the system bulkiness and free-space optical components being sensitive to acoustical and mechanical disturbances. Moreover, the cavity mirror could not be modulated at rates higher than $100 \mathrm{kHz}$, which often limited the application of the system to carrier tracking loops only. Over the years, several heterodyne systems have also been reported, demonstrating, for instance, phase-locking of He-Ne lasers at $5 \mathrm{MHz}$ offset from the reference laser [43], or phase-locking of two diode-laserpumped solid-state Nd:YAG lasers with a difference frequency tuneable in bands from $6 \mathrm{GHz}$ to $34 \mathrm{GHz}$ [44].

All of these systems were realised using very narrowlinewidth lasers; thus the implemented loop bandwidth was not limited by the phase-error propagation delay. This changed 
TABLE I

OVERVIEW OF OPLL Systems BASEd ON SEMICONDUCTOR LASERS, Without LinEWIDTH NARROWING TECHNIQUeS

\begin{tabular}{|c|c|c|c|c|c|c|c|c|}
\hline System & Technology & $\begin{array}{c}\text { Slave laser } \\
\text { type; } \\
\text { FWHM linewidth; } \\
\text { optical power } \\
\end{array}$ & $\begin{array}{c}\text { Master laser } \\
\text { type; } \\
\text { FWHM linewidth; } \\
\text { optical power }\end{array}$ & $\begin{array}{l}\text { time } \\
\text { delay }\end{array}$ & $\begin{array}{c}\text { loop } \\
\text { bandwidth }\end{array}$ & $\begin{array}{l}\text { operating } \\
\text { frequency }\end{array}$ & $\begin{array}{c}\text { residual phase noise } \\
\text { level } \\
\text { phase noise PSD; } \\
\text { phase noise variance }\end{array}$ & $\begin{array}{c}\text { electronic circuit and } \\
\text { loop filter }\end{array}$ \\
\hline I & $\begin{array}{l}\text { free-space optics } \\
\text { [48] }\end{array}$ & $\begin{array}{l}\text { CSP-type LD; } \\
830 \mathrm{~nm} \\
7.5 \mathrm{MHz}\end{array}$ & \begin{tabular}{|l|} 
CSP-type LD; \\
$830 \mathrm{~nm} ;$ \\
7.5 MHz reduced \\
to $150 \mathrm{kHz}$
\end{tabular} & $1 \mathrm{~ns}$ & $134 \mathrm{MHz}$ & homodyne & $0.15 \mathrm{rad}^{2}$ & active loop filter \\
\hline II & $\begin{array}{l}\text { bulk optics } \\
\text { [49] }\end{array}$ & \multicolumn{2}{|c|}{$\begin{array}{c}\text { two DQW-SCH metal clad ridge } \\
\text { waveguide; } 2.5 \mathrm{MHz} \text { (free-running } \\
\text { heterodyne linewidth) }\end{array}$} & $3 \mathrm{~ns}$ & $20 \mathrm{MHz}$ & $5-7 \mathrm{GHz}$ & $\begin{array}{c}1.02 \mathrm{rad}^{2} \\
\text { (500 MHz bandwidth) }\end{array}$ & split path filter \\
\hline III & $\begin{array}{c}\text { miniature bulk optics } \\
{[50],[51]}\end{array}$ & $\begin{array}{l}\text { three-electrode } \\
\text { DFB; } \\
1.5 \mathrm{um} ; \\
6 \mathrm{MHz} \\
\end{array}$ & $\begin{array}{l}\text { three-electrode } \\
\text { DFB; } \\
1.5 \mathrm{um} \\
2 \mathrm{MHz} \\
\end{array}$ & $0.4 \mathrm{~ns}$ & $180 \mathrm{MHz}$ & $3-18 \mathrm{GHz}$ & $\begin{array}{c}<-102 \mathrm{dBc} / \mathrm{Hz} \\
0.04 \mathrm{rad}^{2} \\
(1 \mathrm{GHz} \text { bandwidth })\end{array}$ & passive low-pass \\
\hline IV & $\begin{array}{l}\text { bulk micro-optics } \\
{[52],[53],[54]}\end{array}$ & \multicolumn{2}{|c|}{$\begin{array}{c}\text { two multi-section InGaAsP MQW } \\
\text { DFB; } 1.3 \text { um; } \\
\text { 1-4 MHz (bias dependent) } \\
15-20 \mathrm{~mW} \\
\end{array}$} & $0.38 \mathrm{~ns}$ & $70 \mathrm{MHz}$ & $7-14 \mathrm{GHz}$ & $\begin{array}{c}-95 \mathrm{dBc} / \mathrm{Hz} \\
\text { at } 50 \mathrm{MHz} \text { offset; } \\
0.05 \mathrm{rad}^{2} \\
\text { (1 GHz bandwidth) }\end{array}$ & $\begin{array}{c}\text { phase-lead } \\
\text { compensated low-pass } \\
\text { filter; discrete and } \\
\text { integrated electronics }\end{array}$ \\
\hline $\mathbf{V}$ & \begin{tabular}{|c|} 
monolithic photonic \\
integration \\
{$[57],[58]$} \\
\end{tabular} & $\begin{array}{l}\text { SG-DBR; } \\
10-50 \mathrm{MHz}\end{array}$ & - & - & $300 \mathrm{MHz}$ & $\begin{array}{l}\text { homodyne } \\
\text { with } 5 \mathrm{GHz} \\
\text { offset }\end{array}$ & $\begin{array}{c}0.03 \mathrm{rad}^{2} \\
\text { (analytically } \\
\text { estimated) }\end{array}$ & $\begin{array}{l}\text { FET-based, second } \\
\text { order loop }\end{array}$ \\
\hline VI & $\begin{array}{l}\text { hybrid photonic } \\
\text { integration } \\
\text { [42], [59] }\end{array}$ & $\begin{array}{l}\text { DBR; } \\
1.5 \mathrm{um} ; \\
1 \mathrm{MHz} \\
10 \mathrm{dBm}\end{array}$ & $\begin{array}{c}<100 \mathrm{kHz} \\
7 \mathrm{dBm} \text { (at the } \\
\text { photodetector) }\end{array}$ & $\begin{array}{c}1 \mathrm{~ns} \\
\text { (P-path) } \\
1.8 \mathrm{~ns} \\
\text { (I-path) }\end{array}$ & - & $2-7 \mathrm{GHz}$ & $\begin{array}{c}-80 \mathrm{dBc} / \mathrm{Hz} \\
\text { at } 10 \mathrm{kHz} \text { offset } \\
\text { (for } 5 \mathrm{GHz} \text { signal) }\end{array}$ & $\begin{array}{l}\text { two-path proportional } \\
\text { and integral; custom } \\
\text { electronics }\end{array}$ \\
\hline VII & \begin{tabular}{|c|} 
monolithic photonic \\
integration \\
{$[26],[61]$}
\end{tabular} & $\begin{array}{l}\text { DBR; } \\
1.5 \mathrm{um} ; \\
1.1 \mathrm{MHz}\end{array}$ & $\begin{array}{l}100 \mathrm{kHz} \\
19 \mathrm{dBm} \text { (at the } \\
\text { input fibre) }\end{array}$ & $\begin{array}{c}1 \mathrm{~ns} \\
\text { (P-path) } \\
1.8 \mathrm{~ns} \\
\text { (I-path) }\end{array}$ & $100 \mathrm{MHz}$ & $2-7 \mathrm{GHz}$ & $\begin{array}{c}-90 \mathrm{dBc} / \mathrm{Hz} \\
\text { at } 20 \mathrm{kHz} \text { offset } \\
\text { (for a } 4 \mathrm{GHz} \text { signal); } \\
0.058 \mathrm{rad}^{2} \\
(1 \mathrm{kHz} \text { to } 10 \mathrm{GHz})\end{array}$ & $\begin{array}{l}\text { two-path proportional } \\
\text { and integral; custom } \\
\text { electronics }\end{array}$ \\
\hline \multirow[b]{3}{*}{ VIII } & \multirow{3}{*}{$\begin{array}{c}\text { monolithic photonic } \\
\text { integration } \\
{[62],[63],[64]}\end{array}$} & \multirow{3}{*}{$\begin{array}{l}\text { SG-DBR; } \\
1.5 \mathrm{um} ; \\
10 \mathrm{MHz}\end{array}$} & \multirow[b]{3}{*}{$<100 \mathrm{kHz}$} & \multirow[b]{3}{*}{$200 \mathrm{ps}$} & $400 \mathrm{MHz}$ & $2-9 \mathrm{GHz}$ & & \multirow{3}{*}{$\begin{array}{l}\text { active filter; digital } \\
\text { electronic integrated } \\
\text { circuit }\end{array}$} \\
\hline & & & & & $500 \mathrm{MHz}$ & $5-25 \mathrm{MHz}$ & & \\
\hline & & & & & $1.1 \mathrm{GHz}$ & homodyne & $\begin{array}{c}-90 \mathrm{dBc} / \mathrm{Hz} \\
\text { at } 10 \mathrm{kHz} \text { offset } \\
\text { (for } 100 \mathrm{MHz} \text { signal } \\
\text { offset) }\end{array}$ & \\
\hline IX & $\begin{array}{c}\text { monolithic photonic } \\
\text { integration } \\
{[65]}\end{array}$ & $\begin{array}{l}\text { SG-DBR; } \\
1.5 \mathrm{um} ; \\
10 \mathrm{MHz}\end{array}$ & $\begin{array}{l}\text { ultra-narrow line } \\
\text { of optical comb, } \\
20 \mu \mathrm{W} \text { (at the } \\
\text { input fibre) }\end{array}$ & - & $400 \mathrm{MHz}$ & $\begin{array}{c}2.9-11 \\
\mathrm{GHz}\end{array}$ & $\begin{array}{c}-80 \mathrm{dBc} / \mathrm{Hz} \\
\text { at } 200 \mathrm{~Hz} \text { offset } \\
\text { (for } 2.9 \mathrm{GHz} \text { signal) }\end{array}$ & $\begin{array}{l}\text { active filter; digital } \\
\text { electronic integrated } \\
\text { circuit }\end{array}$ \\
\hline $\mathbf{X}$ & $\begin{array}{c}\text { foundry fabricated } \\
\text { PIC; } \\
\text { [this paper] }\end{array}$ & $\begin{array}{c}\text { DBR; } \\
1.5 \mathrm{um} ; \\
1.25 \mathrm{MHz} ; \\
0 \mathrm{dBm}(\text { at the } \\
\text { output fibre) }\end{array}$ & $\begin{array}{l}100 \mathrm{kHz} \\
-13 \mathrm{dBm} \text { (at the } \\
\text { input fibre) }\end{array}$ & $1.7 \mathrm{~ns}$ & $100 \mathrm{MHz}$ & 4-12 GHz & $\begin{array}{c}-100 \mathrm{dBc} / \mathrm{Hz} \\
\text { at } 10 \mathrm{kHz} \text { offset } \\
\text { (for a } 8 \mathrm{GHz} \text { signal); } \\
0.012 \mathrm{rad}^{2} \\
(1 \mathrm{kHz} \text { to } 1 \mathrm{GHz})\end{array}$ & $\begin{array}{l}\text { passive low pass filter; } \\
\text { COTS SMA- } \\
\text { connectorised analog } \\
\text { electronics }\end{array}$ \\
\hline
\end{tabular}

with the introduction of semiconductor laser diodes into OPLL systems, which enabled a breakthrough in terms of system dimensions and laser tuneability through direct current injection. However the wider laser linewidth of semiconductor lasers (up to $50 \mathrm{MHz}$ ) created a significant issue that needed to be properly addressed.

The first heterodyne system based on two semiconductor lasers achieved only short-term stable locking when an additional external-cavity was implemented [40], [41]. However, such a line-narrowing technique came at the cost of reduced ability to tune the lasers with current, as well as the introduction of frequency jitter into the signal due to acoustic vibration of the external-cavity mirrors. In an experiment aimed at achieving coherent power combination, two external-cavity semiconductor lasers with 3-dB linewidths of $0.5 \mathrm{MHz}$ were phase-locked at $850 \mathrm{MHz}$ from a common reference [17]. The loop propagation delay of the OPLL was about $5 \mathrm{~ns}$; however, the loop bandwidth was severely limited to about $3 \mathrm{MHz}$ by the characteristic phase reversal of the FM response of the laser due to competing thermal and free carrier effects [33], [45]. Another linewidthnarrowing technique employed high finesse resonators to stabilise the semiconductor laser, offering an unlocked heterodyne signal linewidth of less than $30 \mathrm{kHz}$ [46], or $20 \mathrm{kHz}$ permitting a group delay time in the loop of approximately 20 ns [47].

Subsequent improvements in the electronic part of the loop and the use of micro-optics allowed a reduction of the loop propagation delay into the ns range, hence increasing the loop natural frequency into the $\mathrm{MHz}$ range. Consequently, several OPLLs based on semiconductor lasers with moderate linewidth and without line narrowing techniques, were realised. Considering this and further progress in photonic integration, an overview of 
the most important milestones in the development of OPLL systems used to phase-stabilise a diode laser is presented in Table I in chronological order. The listed systems are compared based on the key parameters in the loop design and characterisation (see Section II).

The first non line-narrowed semiconductor laser diode OPLL was implemented in an homodyne system with less than $1 \mathrm{~ns}$ delay and $134 \mathrm{MHz}$ bandwidth, allowing an $830 \mathrm{~nm}$ wavelength slave laser with 7.5 MHz linewidth to be phase-locked [48]. This demonstration - included as System I in Table I - proved that an OPLL based on a slave semiconductor laser operating without a linewidth-narrowing technique could be realised albeit with rather higher phase noise variance. The first experimental demonstration of an heterodyne OPLL, using semiconductor lasers, without any linewidth-narrowing methods reported phase-locking of $830 \mathrm{~nm}$ wavelength lasers with offset frequencies from $5 \mathrm{GHz}$ to $7 \mathrm{GHz}$. System II in Table I was realised with $3 \mathrm{~ns}$ loop propagation delay and $20 \mathrm{MHz}$ bandwidth [49]. Similar solutions based on semiconductor lasers operating at $1.5 \mu \mathrm{m}$, the wavelength around which silica optical fibres have the lowest loss coefficient, proved the ability to generate carriers in a continuous range between $3 \mathrm{GHz}$ and $18 \mathrm{GHz}$. The OPLL included in Table I as System III had a bandwidth of $180 \mathrm{MHz}$, and propagation delay was assessed at the level of 400 ps. Such a small delay was achieved thanks to the implementation of a passive low-pass filter and miniature bulk optics [50], [51].

The first fully packaged OPLL based on two semiconductor lasers functioned as a microwave photonic transmitter generating carriers in the range of $7 \mathrm{GHz}$ to $14 \mathrm{GHz}$ [52], [53]. System IV in Table I was based on two lasers with a free-running summed linewidth of $6 \mathrm{MHz}$, and the OPLL had a feedback bandwidth of $70 \mathrm{MHz}$. The total estimated loop propagation delay was below $0.4 \mathrm{~ns}$, thanks to the micro-optic solutions applied. In consequence, a noteworthy performance was obtained, with a total phase-error variance of $0.05 \operatorname{rad}^{2}$ [54].

\section{INTEGRATION ON INP}

Over the last decade, progress in the design and fabrication of integrated photonic devices has enabled wider tuneability of semiconductor lasers [55] and even sub-MHz linewidths [56], thus potentially relaxing the requirement for extremely broadbandwidth OPLLs. Moreover, a considerable effort has gone into implementing advanced integration technologies, including the introduction of photonic integrated circuits (PICs) comprising numerous optical components integrated onto a single chip, allowing the physical length of the critical path between the SL and the PD to be reduced to a minimum of tens of picoseconds. Developments related to the InP platform, which inherently support light generation, were of the greatest significance. They resulted in one of the first integrated OPLLs suited for laser homodyne and offset locking to the $5 \mathrm{GHz}$ sideband generated by an on-chip modulator. System V included in Table I was based on an InP PIC consisting of two sampled-grating DBR (SG-DBR) lasers, semiconductor optical amplifiers (SOAs), phase modulators, balanced photodetectors, and MMI couplers/splitters [57]. The loop was estimated to have $300 \mathrm{MHz}$ bandwidth and the

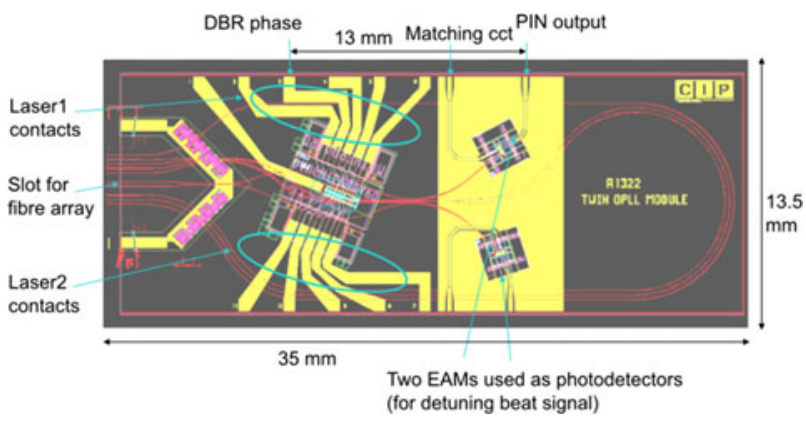

Fig. 4. Layout of motherboard for hybrid integration (red lines are optical waveguides, yellow are electrical connections) [42].

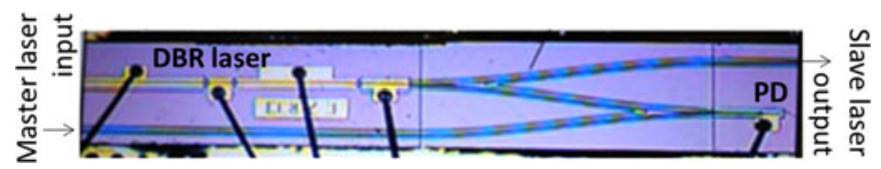

Fig. 5. OPLL photonic integrated circuit containing DBR laser and PD [26].

ability to suppress phase noise in the heterodyne signal to an estimated value of phase-error variance of $0.03 \mathrm{rad}^{2}$ [58].

System VI in Table I refers to the first twin-OPLL system, which was designed to phase-lock two DBR lasers to the separate lines of an optical comb with variable frequency offset, introducing the concept of a compact continuously tuneable photonic oscillator for high-purity $\mathrm{THz}$ signal generation [59]. The hybrid integration platform was used to integrate active InGaAsP components onto a daughter board with silica waveguides and electrical connection, which was then flip-chip bonded to a silicon motherboard (see Fig. 4). The delay caused by the optical path was reduced to less than 50 ps. Although the electronic part of the loop still contributed $1 \mathrm{~ns}$ of delay [60], the OPLL was able to phase-lock a laser with $1 \mathrm{MHz}$ linewidth. The synthesised heterodyne signal achieved phase noise lower than $-80 \mathrm{dBc} / \mathrm{Hz}$ at an offset of $10 \mathrm{kHz}$ [42]. The electronic circuit used in this system included also auxiliary circuitry for lock detection and lock acquisition [60].

Subsequently, System VII in Table I was built using the same custom-made, logic electronic circuit with dual-path loop filter as System VI. However, the optical path between the SL and photodiode was further reduced to $15 \mathrm{ps}$, thanks to monolithic photonic integration of two DBR lasers, photodiodes and optical waveguides [61]. The components on the PIC were arranged in such a way as to form a dual-arm OPLL used in an heterodyne system to generate high spectral purity signals of up to $50 \mathrm{GHz}$ [61]. At the same time, a single OPLL (see Fig. 5) based on the same components was also realised as a generic OPLL reported in [26]. With the loop in operation, phase-error variances between $0.038 \mathrm{rad}^{2}$ and $0.22 \mathrm{rad}^{2}$ were achieved within a bandwidth of $1 \mathrm{kHz}$ to $10 \mathrm{GHz}$, depending on offset-locking frequency. The phase noise of the heterodyne signal was suppressed to below $-90 \mathrm{dBc} / \mathrm{Hz}$ for frequency offsets greater than $10 \mathrm{kHz}$ [26], and later improved to below $-93 \mathrm{dBc} / \mathrm{Hz}$ for offsets above $10 \mathrm{kHz}$ [32], thanks to loop filter refinements.

Improvements in the electronic circuitry of the loop have also been substantial and have had equally positive effects on the developments of OPLLs. In the System VIII in Table I, 


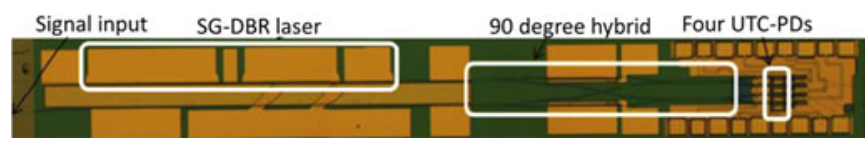

Fig. 6. A microscope picture of PIC integrating SG-DBR laser, star coupler, photodetectors, and microstrip transmission lines [63].

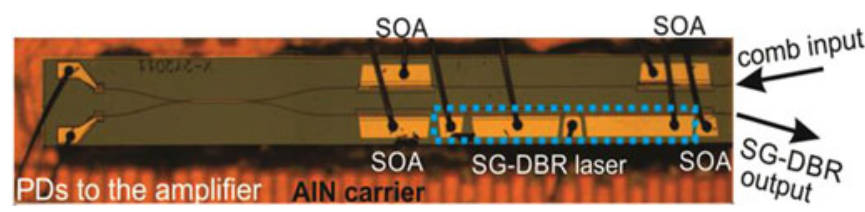

Fig. 7. A microscope picture of the PIC [65] included as system IX in Table I.

OPLL performance was improved by reducing the loop propagation delay to $200 \mathrm{ps}$. This was achieved by integration as the PIC was combined with an all-digital InP HBT electronic integrated circuit (EIC) [29]. Such a level of integration was also necessary because a loop with particularly broad bandwidth was required to phase-lock a SG-DBR laser with $10 \mathrm{MHz}$ linewidth [62], [29]. This OPLL was demonstrated in optical coherent communication applications [63]. The PIC integrates not only a widely-tunable SG-DBR laser and four high-speed PDs but it also incorporates an optical 90 degree hybrid on the InGaAsP/InP platform, as shown in Fig. 6.

The SL was locked on both sides of the reference laser frequency at an offset frequency ranging between $-2 \mathrm{GHz}$ and $-9 \mathrm{GHz}$ on one side of the $\mathrm{ML}$ and from $+2 \mathrm{GHz}$ to $+7.5 \mathrm{GHz}$ on the other [62]. The offset locking was further increased to $25 \mathrm{GHz}$ frequency, which was defined and effectively limited by the RF signal generator, the frequency of which needs to be twice the desired offset frequency of this heterodyne OPLL [64].

Most recently, the EIC was also integrated with the InGaAsP/InP PIC presented in Fig. 7 (consisting of a SG-DBR laser, $2 \times 2$ multi-mode interference (MMI) coupler, two SOAs and two high-speed quantum well (QW)-based waveguide photodetectors [65]. This OPLL, included in Table I as System IX was used for frequency synthesis by phase locking to an optical comb, as previously proposed in [13].

All of the integrated OPLLs mentioned so far were created by one-off dedicated fabrication processes, which require significant amount of time and financial resources to be invested before the PIC can be realized. However, the most recent demonstration of an OPLL (System X in Table I) uses an alternative approach of generic foundry PIC fabrication at Oclaro, UK. This OPLL consists of a PIC integrating DBR laser, SOA, two PIN photodiodes, waveguides and MMI couplers. The InP-based PIC was assembled with off-the-shelf electronic components to build an OPLL that allows generation of heterodyne signals at frequencies up to $12 \mathrm{GHz}$ with phase noise of less than $-100 \mathrm{dBc} / \mathrm{Hz}$ at $10 \mathrm{kHz}$ offset from the carrier. This OPLL has delivered the lowest phase noise heterodyne signal obtained by monolithically integrated OPLLs. The foundry OPLL implementation is presented in more detail in the next section.

\section{FOUNDRY FABRICATED OPLL}

The most recent development resulting from continuous improvements of InP-based epitaxial growth and fabrication technologies is the development of a new approach to the design and fabrication of photonic integrated circuits [66]. PIC fabrication based on the generic foundry concept allows numerous integrated circuits from different designers to be fabricated at the same time on a multi-project wafer using common fabrication processes [67]. Thanks to this approach, both the time required to realize a prototype and the overall cost can be reduced very significantly.

One of the strengths of the generic foundry approach over dedicated fabrication is the increased repeatability of the chip manufacturing process. This allows for improvement in the performance of each photonic component offered by the foundry as building blocks. The foundry-fabricated OPLL presented in this paper can be stably locked to a ML signal level of only $-13 \mathrm{dBm}$ (measured at the output of the lensed fibre used), which is significantly less than the $22 \mathrm{dBm}$ required by OPLLs reported in [61]. This is of particular importance in applications where the OPLL is used as a high quality "optical filter" to select individual lines from an optical frequency comb, which typically has moderate total output power that is distributed across numerous comb lines, resulting in $\mu \mathrm{W}$ power level per single comb line. The smaller requirement for ML power in System X can be related to better fiber to PIC coupling, smaller waveguide and coupler/splitter propagation losses and improved responsivity of the photodiode.

To perform its function in the OPLL, the PIC containing DBR lasers and PIN photodiodes was accommodated on a carrier on an alumina board containing the DC and coplanar waveguide lines. Subsequently, an interface PCB was included, to enable the electrical connections to the integrated photonic components and to match the dimensional difference between the $70 \mu \mathrm{m}$ width microstrip lines on the alumina board and SMA connectors. The interface PCB also included circuits to drive the SL phase section, bias-tees to provide reverse voltage bias to PDs and a low pass filter. The $-3 \mathrm{~dB}$ bandwidth of PD and PS electrical connection paths, located on the matching $\mathrm{PCB}$ were measured to be $16 \mathrm{GHz}$ and $2 \mathrm{GHz}$, respectively. The total propagation delay related to the interface board was $600 \mathrm{ps}$. The feedback loop electronic components were connected to the interface PCB shown in Fig. 8. The optical signal to and from the PIC was coupled using lensed fibres at both ends of the chip.

The OPLL electronic feedback path consists of i) bias tee to provide reverse bias voltage to the integrated $\mathrm{PD}$, ii) a low-noise $\mathrm{RF}$ amplifier included to boost the power of the phase error signal, iii) a phase detector, iv) a low-pass filter and v) a bias circuit for the laser PS. The gain of this low-noise control amplifier is adjustable, offering a mechanism capable of controlling the loop gain within the operating heterodyne frequency range of $2 \mathrm{GHz}$ to $16 \mathrm{GHz}$. The RF amplifier contributes $350 \mathrm{ps}$ to the total loop delay. The phase detector is a commercially available SMA connectorised double-balanced mixer, which offers wide bandwidth $(4 \mathrm{GHz}-12 \mathrm{GHz})$ and a short delay of $310 \mathrm{ps}$. 


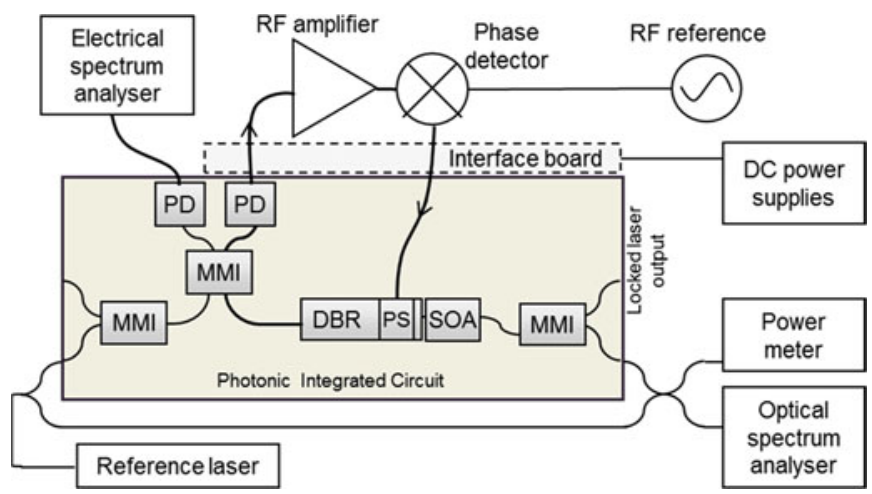

Fig. 8. Schematic diagram of the optical phase lock loop assembly.

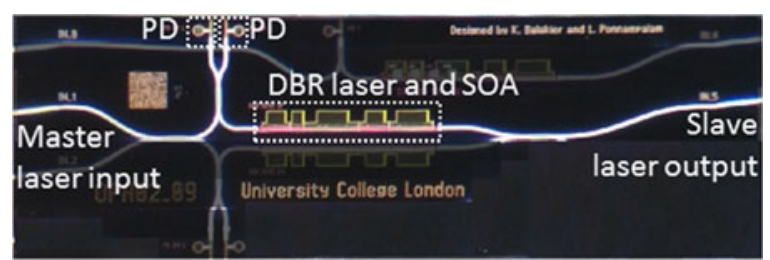

Fig. 9. Photographs of OPLL PIC with dimensions of $2 \mathrm{~mm} \times 6 \mathrm{~mm}$. All components that do not form part of the OPLL are greyed out.

This compact OPLL circuit with precise gain control has bandwidth of $100 \mathrm{MHz}$ and a total loop delay of $1.7 \mathrm{~ns}$ and is capable of heterodyne tuning from $4 \mathrm{GHz}$ to $12 \mathrm{GHz}$.

\section{A. Photonic Integrated Circuit}

The InP based PIC was fabricated on n-doped wafer, thinned to $135 \mu \mathrm{m}$ and subsequently cleaved to $2 \mathrm{~mm} \times 6 \mathrm{~mm}$ in size. A single chip contains a total of 33 components, including active and passive structures. Fig. 9 shows a picture of the fabricated OPLL die, which could be used to realise up to 3 individual OPLLs, depending on the configuration of the electrical connections and the required application.

The optical connection between the DBR laser and PD has been made using deeply etched ridge waveguide with lengths less than $1.2 \mathrm{~mm}$ to reduce the losses and propagation delay within feedback loop. Furthermore, all splitters/couplers used in the OPLL PIC were $2 \times 2$ MMI couplers, offering superior performance in terms of wide optical bandwidth, low loss, insignificant polarisation dependence and relaxed fabrication requirements, when compared to alternative solutions such as Y-junctions or directional couplers [68].

1) Photodiode: The PIC photodiodes are side-illuminated PIN photodiodes fabricated in a deep-etched waveguide and offer responsivity of approximately $0.8 \mathrm{~A} / \mathrm{W}$. To enable efficient operation in the $\mathrm{GHz}$ range, the $\mathrm{PD}$ in the feedback loop was biased at $-9 \mathrm{~V}$ producing up to $5 \mathrm{~mA}$ of photocurrent when illuminated with the integrated DBR laser and $200 \mu \mathrm{A}$ of photocurrent for $6 \mathrm{dBm}$ (in lensed fibre) power from the master laser. These currents levels also demonstrate the superior performance of the presented OPLL PIC over previously demonstrated OPLLs that offered $18 \mu \mathrm{A}$ (for $22 \mathrm{dBm}$ optical power in fibre) [61]. It should also be noted that the ML signal passes through two MMI couplers on the PIC before it reaches the PD.

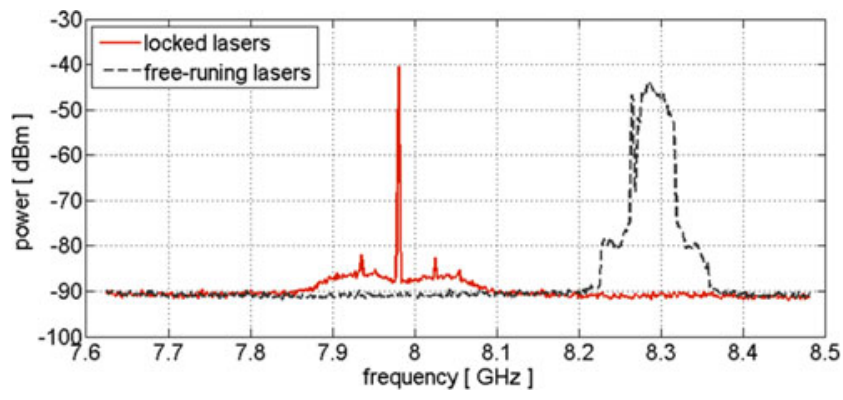

Fig. 10. Electrical spectra of the phase locked and free running heterodyne signal. $\mathrm{RBW}=300 \mathrm{kHz}, \mathrm{VBW}=30 \mathrm{kHz}, \mathrm{SWT}=0.09 \mathrm{~s}$. Measurements present 50 sweeps in max-hold trace mode.

2) Semiconductor Laser Diode: The DBR laser consists of four sections that include a multi-quantum well section to provide gain, a phase control section and two identical modeselective grating filters with $60 \%$ reflectivity, one at the front and one at the rear of the laser. Each laser section is controlled by a separate electrode. The laser optical power is expected to be in the region of $7.5 \mathrm{~mW}$ and wavelength is centered at approximately $1.53 \mu \mathrm{m}$. Furthermore, an integrated SOA was implemented at the output of the DBR laser, with the aim of enhancing the optical signal before it was coupled to the optical fibre. A self-heterodyne interferometer technique with $5 \mathrm{~km}$ delay optical path [69] was used to measure the laser linewidth and gave a result of $1.25 \mathrm{MHz}$.

The DBR laser PS can be used through current tuning for fine wavelength adjustment of up to $0.4 \mathrm{~nm}(50 \mathrm{GHz})$. The laser PS tuning sensitivity was measured to be up to $-0.35 \mathrm{~nm} / \mathrm{mA}$ (45 GHz/mA) at DC, offering a value that is sufficient for the overall gain in the loop [13]. The FM response of the laser was also characterised and measured and had a $3 \mathrm{~dB}$ bandwidth of $100 \mathrm{MHz}$ which will limit the overall achievable bandwidth of the feedback loop.

\section{B. Experimental Results}

The DBR slave laser is phase stabilised by reference to the master laser coupled to the PIC through a lensed fibre aligned to the optical waveguide with spot size converter. The ML signal is guided on the ridge waveguide into a $2 \times 2$ MMI coupler which combines the slave and master laser signals and splits these signals between two waveguides connected to the pair of PDs. One of the PD pairs is used to detect the phase-error signal processed by the feedback loop, while the other is used for lock monitoring purposes and its output is connected to an electrical spectrum analyser (ESA). The heterodyne measured on the ESA is presented in Fig. 10, demonstrating the difference in linewidth and peak power of the free running and locked signal for an offset frequency of $8 \mathrm{GHz}$.

When the feedback loop was disabled, the linewidth of the free running heterodyne signal was in the tens of $\mathrm{MHz}$ range and the frequency jitter was over approximately $100 \mathrm{MHz}$ range. This behaviour is due to the combined linewidth and wavelength fluctuation of the reference and DBR lasers, even though an external cavity laser with $<100 \mathrm{kHz}$ linewidth was used as a reference source. 


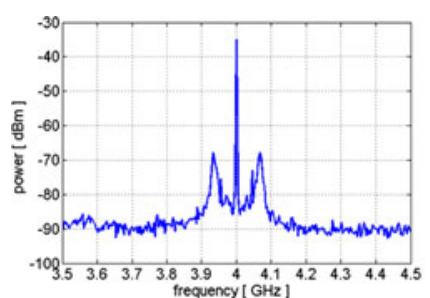

(a)

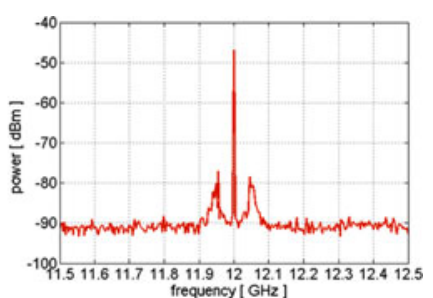

(b)
Fig. 11. Electrical spectra of heterodyne signal measured at $4 \mathrm{GHz}$ (a), and $12 \mathrm{GHz}$ (b) frequency offset between the two lasers. RBW $=500 \mathrm{kHz}$, $\mathrm{VBW}=100 \mathrm{kHz}$.

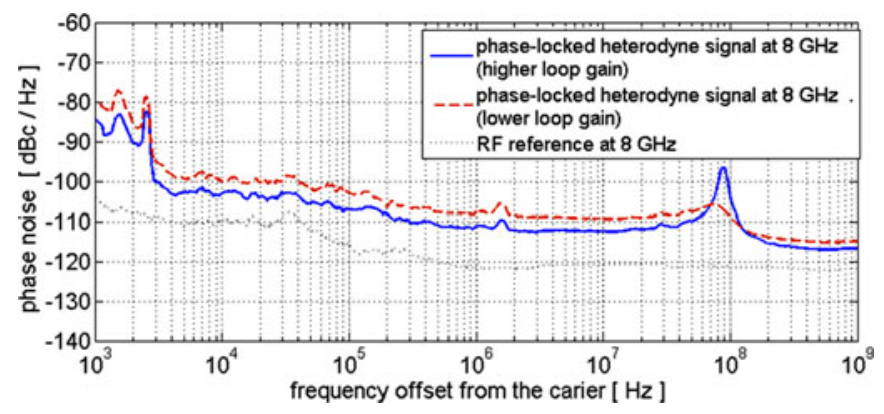

Fig. 12. The SSB phase noise spectra of the phase locked heterodyne signal at $8 \mathrm{GHz}$.

Due to the loop design, the DBR laser can be phase locked to the incoming signal with any frequency offset between $4 \mathrm{GHz}$ and $12 \mathrm{GHz}$, as shown in Fig. 11. The offset frequency is limited at the lower end by the bandwidth of the dual-balanced mixer used as the phase detector and at the higher frequency end by the bandwidth of the PD.

To further assess the quality of phase locking, the singlesideband phase noise spectra of the heterodyne signal were measured for two different loop gains. The phase noise achieved was below $-100 \mathrm{dBc}$ at $10 \mathrm{kHz}$ frequency offset from the carrier (see Fig. 12). This leads to a phase-error variance of the generated heterodyne signal as low as $0.012 \mathrm{rad}^{2}$ for offsets between $1 \mathrm{kHz}$ to $1 \mathrm{GHz}$, for the plot with lower loop gain in Fig. 12 .

Fig. 12 also demonstrates the effect of loop gain variation and the importance of optimisation. In general, an OPLL with too little gain cannot sufficiently suppress phase noise at lower frequency offsets from the carrier. On the other hand, higher loop gain offers further phase noise reduction closer to the carrier, however a secondary peak at a frequency close to the loop bandwidth becomes visible in the phase noise spectrum that can potentially increase the overall phase variance. The measurements presented in Fig. 12 suggest that the OPLL closed loop bandwidth is about $100 \mathrm{MHz}$.

\section{Future PROSPeCtS}

The stability of semiconductor laser OPLLs is closely related to the loop delay, which creates the necessity for photonic integration to reduce optical path length. Further to that, small dimension electronics and the use of passive or dual-path loop filters are essential for the stable operation of OPLLs based on semiconductor lasers. With the optical path on the photonic chip being shorter than a couple of millimetres it is evident that further integration of the electronics is key to improved performance. In the longer term, this is expected to lead to the integration of photonic and electronic components on a single substrate.

The ongoing development of monolithic microwave integrated circuits (MMICs) creates a growing library of components that could be implemented within OPLL. These circuits may be based on silicon, InP, GaAs or SiGe technology, and, even though each of them has its own advantages and limitations, they provide functionalities of numerous discrete components such as mixers, low-noise amplifiers and filters, however integrated on a single substrate. The System VIII and IX in Table I are fine examples of OPLLs in which some functions of the loop electronics were realised using the InP HET and SiGe elements respectively, demonstrating delay of hundreds of picoseconds due to this EIC part of the loop [29], [65].

The technology which can create the greatest prospects for future OPLL systems foresees the integration of photonic and electronic components on a silicon substrate. The greatest strengths of silicon that make silicon-based circuits suited for high volume production are its robustness, highly competitive cost of processing and a larger wafer area compared with III-V compound semiconductors. Silicon is highly attractive as it is the material traditionally used for electronic integrated circuits. Silicon photonics is regarded by some as the most developed technology for photonic integrated circuits, given it offers guidance of light, modulation, polarisation, phase and wavelength conversion functionalities [70], [71]. The strength of silicon-on-insulator (SOI) waveguides comes from high index contrast between silicon and $\mathrm{SiO}_{2}$ resulting in strong optical confinement and relatively low losses down to $0.1-0.5 \mathrm{~dB} / \mathrm{cm}$ [72]. This allows for compact layouts and tight bends, hence miniaturisation and large-scale integration of SOI photonic circuits, as demonstrated in [73], [74]. So far, the biggest drawback of silicon is its indirect band gap, which makes it unsuitable for fabricating efficient laser diodes and amplifiers. This problem is however expected to be addressed in the near future as a number of promising solutions are being investigated. These include research on better light coupling from external lasers [75], die bonding of gain material on a silicon photonic waveguide circuit [76] or direct growth of quantum dot active layers for laser fabrication directly on silicon [77]. Before tight integration of electronics and photonics on-chip becomes widely available some issues related with complex co-design and co-fabrication are still to be solved [78]. Nevertheless, such monolithic integration would not only improve the loop stability but also result in a reduction of volume and weight of a single OPLL, thus making such systems more robust and cost efficient and therefore more suitable for high-volume applications.

\section{CONCLUSION}

In this paper, we have described OPLL systems together with their critical parameters and design considerations. We have also described the development of several OPLLs, which were enabled through advances in photonic integration. The impact of 
photonic integration is evident in reduction of OPLL footprint, but most importantly in the reduction in heterodyne phase noise, increase in loop stability and reduced sensitivity to vibration and temperature changes.

Moreover, we have presented in this paper the first OPLL based on a PIC fabricated using a generic foundry process. The performance of this OPLL in terms of control of the phase noise of the semiconductor laser matches that achieved by the best previously reported semiconductor laser OPLLs. The phase noise of the generated heterodyne signal was measured below $-100 \mathrm{dBc} / \mathrm{Hz}$ at $10 \mathrm{kHz}$ offsets from the carrier, a record result for a monolithically integrated OPLL. Moreover, the unique layout of the PIC and the maturity of the generic foundry process in fabricating waveguides and interconnects resulted in greatly reduced reference laser power requirements for the stable operation of the OPLL.

Finally, we foresee that further improvements in OPLL performance can be achieved through monolithic photonic and electronic integration, which may soon be feasible thanks to the efforts being made to obtaining monolithically integrated laser and amplifier functionalities on silicon.

\section{REFERENCES}

[1] L. H. Enloe and J. L. Rodda, "Laser phase-locked loop," Proc. IEEE, vol. 53, no. 2, pp. 165-166, Feb. 1965.

[2] W. R. Leeb, H. K. Philipp, A. L. Scholtz, and E. Bonek, "Frequency synchronization and phase locking of $\mathrm{CO}_{2}$ lasers," Appl. Phys. Lett., vol. 41, no. 7, 1982, Art. no. 592.

[3] M. Ohtsu, Highly Coherent Semiconductor Lasers. Norwood, MA, USA: Artech House, 1992.

[4] C. J. Buczek, R. J. Freiberg, and M. L. Skolnick, "Laser injection locking," Proc. IEEE, vol. 61, no. 10, pp. 1411-1431, Oct. 1973.

[5] K. Balakier et al., "Optical injection locking of monolithically integrated photonic source for generation of high purity signals above $100 \mathrm{GHz}$," Opt. Express, vol. 22, no. 24, pp. 29404-29412, 2014.

[6] S. Fukushima, C. Silva, Y. Muramoto, and A. J. Seeds, "Optoelectronic millimeter-wave synthesis using an optical frequency comb generator, optically injection locked lasers, and a unitraveling-carrier photodiode," J. Lightw. Technol., vol. 21, no. 12, pp. 3043-3051, Dec. 2003.

[7] O. Lidoyne, P. Gallion, C. Chabran, and G. Debarge, "Locking range, phase noise and power spectrum of an injection-locked semiconductor laser," IEE Proc. J. Optoelectron., vol. 137, no. 3, pp. 147-154, Jun. 1990.

[8] M. J. Fice, A. Chiuchiarelli, E. Ciaramella, and A. J. Seeds, "Homodyne coherent optical receiver using an optical injection phase-lock loop," $J$. Lightw. Technol., vol. 29, no. 8, pp. 1152-1164, Apr. 2011.

[9] Y. Shoji, M. J. Fice, Y. Takayama, A. J. Seeds, and A. A. Leo, “A pilotcarrier coherent LEO-to-Ground downlink system using an optical injection phase lock," J. Lightw. Technol., vol. 30, no. 16, pp. 2696-2706, Aug. 2012.

[10] G. J. Schneider, J. A. Murakowski, C. A. Schuetz, S. Shi, and D. W. Prather, "Radiofrequency signal-generation system with over seven octaves of continuous tuning," Nature Photon., vol. 7, pp. 118-122, 2013.

[11] K. Kikuchi, T. Okoshi, M. Nagamatsu, and N. Henmi, "Degradation of bit-error rate in coherent optical communications due to spectral spread of the transmitter and the local oscillator," J. Lightw. Technol., vol. 2, no. 6, pp. 1024-1033, Dec. 1984.

[12] L. Kazovsky, "Performance analysis and laser linewidth requirements for optical PSK heterodyne communications systems," J. Lightw. Technol., vol. 4, no. 4, pp. 415-425, Apr. 1986.

[13] K. Balakier, M. J. Fice, L. Ponnampalam, A. J. Seeds, and C. C. Renaud, "Monolithically integrated optical phase lock loop for microwave photonics," J. Lightw. Technol., vol. 32, no. 20, pp. 3893-3900, Oct. 2014.

[14] A. Rolland et al., "Optoelectronic phase-locked loop for millimeter-wave and THz beat note stabilization," Proc. SPIE, vol. 8496, 2012, Art. no. $84960 \mathrm{H}$.
[15] B. Widiyatmoko, M. Kourogi, and M. Ohtsu, "Linking two optical frequency combs by heterodyne optical phase locking between diode lasers at 2.6-THz frequency-difference," IEEE Photon. Technol. Lett., vol. 11, no. 4, pp. 460-462, Apr. 1999.

[16] T. Nagatsuma, N. Kukutsu, and Y. Kado, "Photonic generation of millimeter and terahertz waves and its applications," in Proc. Int. Conf. Appl. Electromagn. Commun., vol. 49, 2007, pp. 51-59.

[17] N. Satyan, W. Liang, A. Kewitsch, G. Rakuljic, and A. Yariv, "Coherent power combination of semiconductor lasers using optical phase-lock loops," J. Sel. Topics Quantum Electron., vol. 15, no. 2, pp. 240-247, 2009 .

[18] A. J. Seeds and K. J. Williams, "Microwave photonics," J. Lightw. Technol., vol. 24, no. 12, pp. 4628-4641, Dec. 2006.

[19] D. Marpaung et al., "Integrated microwave photonics," Laser Photon. Rev., vol. 7, no. 4, pp. 506-538, 2012.

[20] A. J. Seeds et al., "Coherent terahertz photonics," Opt. Express, vol. 21, no. 19 , pp. 22988-23000, Sep. 2013.

[21] H. R. Telle, D. Meschede, and T. W. Hänsch, "Realization of a new concept for visible frequency division: Phase locking of harmonic and sum frequencies," Opt. Lett., vol. 15, no. 10, pp. 532-534, 1990.

[22] S. Hisatake, J. Y. Kim, K. Ajito, and T. Nagatsuma, "Self-heterodyne spectrometer using uni-traveling-carrier photodiodes for terahertz-wave generators and optoelectronic mixers," J. Lightw. Technol., vol. 32, no. 20, pp. 3683-3689, Oct. 2014.

[23] B. Shillue, S. AlBanna, and L. D. Addario, "ALMA memo 483: The ALMA 1st local oscillator reference," [Online]. Available: http://library.nrao.edu/alma.shtml. Accessed on: Sep. 2015, 2004.

[24] Y. Sekimoto et al., "ALMA memo 449: Noise evaluation of hybrid photonic local oscillator at $500 \mathrm{GHz}$," [Online]. Available: http://library.nrao.edu/alma.shtml. Accessed on: Sep. 2015, 2003.

[25] H. Park et al., "40 Gbit/s coherent optical receiver using a Costas loop," Opt. Express, vol. 20, no. 26, pp. B197-B203, Dec. 2012.

[26] R. J. Steed et al., "Monolithically integrated heterodyne optical phaselock loop with RF XOR phase detector," Opt. Express, vol. 19, no. 21, pp. 20048-20053, Oct. 2011.

[27] R. T. Ramos and A. J. Seeds, "Delay, linewidth and bandwidth limitations in optical phase-locked loop design," Electron. Lett., vol. 3, pp. 389-391, 1990.

[28] M. A. Grant, W. C. Michie, and M. J. Fletcher, "The performance of optical phase-locked loops in the presence of nonnegligible loop propagation delay," J. Lightw. Technol., vol. LT-5, no. 4, pp. 592-597, Apr. 1987.

[29] E. Bloch et al., "A 1-20-GHz all-digital InP HBT optical wavelength synthesis IC," Trans. Microw. Theory Techn., vol. 61, no. 1, pp. 570-580, Jan. 2013.

[30] R. T. Ramos and A. J. Seeds, "Comparison between first-order and secondorder optical phase-lock loops," Microw. Guid. Wave Lett., vol. 4, no. 1, pp. 7-9, 1994.

[31] F. M. Gardner, Phaselock Techniques. Hoboken, NJ, USA: Wiley, 2005.

[32] K. Balakier, M. J. Fice, L. Ponnampalam, C. C. Renaud, and A. J. Seeds, "Tuneable monolithically integrated photonic THz heterodyne system," in Proc. Int. Topical Meeting Microw. Photon., 2012, pp. 286-289.

[33] P. Correc, O. Girard, and I. Faria, "On the thermal contribution to the FM response of DFB lasers: Theory and experiment," J. Quantum Electron., vol. 30, no. 11 , pp. 2485-2490, 1994.

[34] M. Okai, M. Suzuki, and M. Aoki, "Complex-coupled $\lambda / 4$-shifted DFB lasers with a flat FM response," IEEE J. Sel. Topics Quantum Electron., vol. 1, no. 2, pp. 461-465, Jun. 1995.

[35] W. F. Walls, "Cross-correlation phase noise measurements," in Proc. Frequency Control Symp., 1992, pp. 257-261.

[36] R. G. Rogers, Low Phase Noise Microwave Oscillator Design. Norwood, MA, USA: Artech House, 1991.

[37] Y. Yamamoto, "AM and FM quantum noise in semiconductor lasers-part I: theoretical analysis," J. Quantum Electron., vol. QE-19, no. 1, pp. 34-46, 1983.

[38] Y. Yamamoto, S. Saito, and T. Mukai, "AM and FM quantum noise in semiconductor lasers-Part II: Comparison of theoretical and experimental results for AlGaAs lasers," J. Quantum Electron., vol. QE-19, no. 1, pp. 47-58, 1983.

[39] G. Pillet et al., "Dual-frequency laser at 1.5 um for optical distribution and generation of high-purity microwave signals," J. Lightw. Technol., vol. 26, no. 15, pp. 2764-2773, Aug. 2008.

[40] R. C. Steele, "Optical phase-locked loop using semiconductor laser diodes," Electron. Lett., vol. 19, no. 2, pp. 69-71, 1982. 
[41] J. Harrison and A. Mooradian, "Linewidth and offset frequency locking of external cavity GaAlAs lasers," J. Quantum Electron., vol. 25, no. 6, pp. 1152-1155, 1989.

[42] R. J. Steed et al., "Hybrid integrated optical phase-lock loops for photonic terahertz sources," J. Sel. Topics Quantum Electron., vol. 17, no. 1, pp. 210-217, 2010.

[43] J. L. Hall, M. A. Long-sheng, and G. Kramer, "Principles of optical phaselocking: Application to internal mirror He-Ne lasers phase-locked via fast control of the discharge current," J. Quantum Electron., vol. QE-23, no. 4, pp. 427-437, 1987.

[44] K. J. Williams, "6-34 GHz offset phase-locking of Nd:YAG $1319 \mathrm{~nm}$ nonplanar ring lasers," Electron. Lett., vol. 25, no. 18, pp. 1242-1243, 1989.

[45] N. Satyan et al., "Phase-controlled apertures using heterodyne optical phase-locked loops," Photon. Technol. Lett., vol. 20, no. 11, pp. 897-899, 2008.

[46] C.-H. Shin and M. Ohtsu, "Heterodyne optical phase-locked loop by confocal Fabry-Perot cavity coupled AlGaAs lasers," IEEE Photon. Technol. Lett., vol. 2, no. 4, pp. 297-300, Apr. 1990.

[47] H. R. Telle and H. Li, "Phase-locking of laser diodes," Electron. Lett., vol. 26 , no. 13 , pp. 1-2, 1990.

[48] M. Kourogi, C.-H. Shin, and M. Ohtsu, "A $134 \mathrm{MHz}$ bandwidth homodyne optical phase-locked-loop of semiconductor laser diodes," Photon. Technol. Lett., vol. 3, no. 3, pp. 270-272, Mar. 1991.

[49] R. T. Ramos and A. J. Seeds, "Fast heterodyne optical phase-lock loop using double quantum well laser diodes," Electron. Lett., vol. 28, no. 1, pp. 82-83, 1992.

[50] U. Gliese et al., "A wideband heterodyne optical phase-locked loop for generation of 3-18 GHz microwave carriers," Photon. Technol. Lett., vol. 4, no. 8, pp. 936-938, 1992.

[51] U. Gliese, T. Nielsen, M. Bruun, E. L. Christensen, and K. E. Stubkjaer, "A 3-18 GHz microwave signal generator based on optical phase locked semiconductor DFB lasers," in Proc. Digest LEOS Summer Topical Meeting, 1993, pp. 5-6.

[52] L. N. Langley et al., "Packaged semiconductor laser optical phase-locked loop (OPLL) for photonic generation, processing and transmission of microwave signals," Trans. Microw. Theory Techn., vol. 47, no. 7, pp. 1257 1264, Jul. 1999.

[53] L. N. Langley et al., "Development of a packaged optical phase locked loop for use as a signal source in phased array communications antennas," Proc. SPIE, vol. 3463, pp. 220-226, 1998.

[54] L. N. Langley et al., "7-14 GHz optical phase-locked loop (OPLL) source module for use in coherent optical beamforming applications," Electron. Lett., vol. 34, no. 24, pp. 2342-2343, 1998.

[55] A. J. Ward et al., "Widely tunable DS-DBR laser with monolithically integrated SOA: design and performance," J. Sel. Topics Quantum Electron., vol. 11, no. 1, pp. 149-156, Jan. 2005.

[56] M. Faugeron et al., "High-power tunable dilute mode DFB laser with low RIN and narrow linewidth," Photon. Technol. Lett., vol. 25, no. 1, pp. 7-10, 2013.

[57] S. Ristic, A. Bhardwaj, M. J. Rodwell, L. A. Coldren, and L. A. Johansson, "Integrated optical phase-locked loop," in Proc. Opt. Fiber Commun. Conf., 2009, pp. 7-9.

[58] S. Ristic, A. Bhardwaj, M. J. Rodwell, L. A. Coldren, and L. A. Johansson, "An optical phase-locked loop photonic integrated circuit," J. Lightw. Technol., vol. 28, no. 4, pp. 526-538, Feb. 2010.

[59] L. Ponnampalam et al., "A compact tunable coherent Terahertz source based on an hybrid integrated optical phase-lock loop," in Proc. Topical Meeting Microw. Photon., 2010, pp. 151-154.

[60] L. Naglic, L. Pavlovic, B. Batagelj, and M. Vidmar, "Improved phase detector for electro-optical phase-locked loops," Electron. Lett., vol. 44, no. 12 , pp. 44-45, 2008.

[61] L. Ponnampalam et al., "Monolithically integrated photonic heterodyne system," J. Lightw. Technol., vol. 29, no. 15, pp. 2229-2234, Aug. 2011.

[62] M. Lu et al., "Highly integrated optical heterodyne phase-locked loop with phase/frequency detection," Opt. Express, vol. 20, no. 9, pp. 1090-1092, 2012.

[63] M. Lu et al., "An integrated $40 \mathrm{Gbit} / \mathrm{s}$ optical costas receiver," J. Lightw. Technol., vol. 31, no. 13, pp. 2244-2253, Jul. 2013.

[64] M. Lu et al., "An integrated heterodyne optical phase-locked loop with record offset locking frequency," in Proc. Opt. Fiber Commun. Conf., 2014, pp. 9-11.

[65] S. Arafin et al., "Towards chip-scale optical frequency synthesis based on optical heterodyne phase-locked loop A wide-range optical frequency generator based on the frequency comb of a femtosecond laser," Opt. Express, vol. 25, no. 2, pp. 1843-1845, 2017.
[66] M. Smit et al., "Generic foundry model for InP-based photonics," IET Optoelectron., vol. 5, no. 5, pp. 187-194, 2011.

[67] M. Smit et al., "An introduction to InP-based generic integration technology," Semicond. Sci. Technol., vol. 29, no. 8, 2014, Art. no. 083001.

[68] L. B. Soldano and E. C. M. Pennings, "Optical multi-mode interference devices based on self-imaging: principles and applications," J. Lightw. Technol., vol. 13, no. 4, pp. 615-627, Apr. 1995.

[69] T. Okoshi, K. Kikuchi, and A. Nakayama, "Novel method for high res olution measurement of laser output spectrum," Electron. Lett., vol. 16, no. 16 , pp. 630-631, 1980.

[70] S. Yegnanarayanan, P. Trinh, F. Coppinger, and B. Jalali, "Compact silicon-based integrated optical time-delay network," Proc. SPIE, vol. 3160, pp. 2-10, 1997.

[71] B. Jalali, M. Paniccia, and G. Reed, "Silicon photonics," IEEE Microw. Mag., vol. 7, no. 3, pp. 58-68, Jun. 2006.

[72] M. S. Rasras et al., "Demonstration of a tunable microwave-photonic notch filter using low-loss silicon ring resonators," J. Lightw. Technol., vol. 27, no. 12, pp. 2105-2110, Jun. 2009.

[73] R. Soref, "The past, present, and future of silicon photonics," J. Sel. Topics Quantum Electron., vol. 12, no. 6, pp. 1678-1687, 2006.

[74] B. Jalali and S. Fathpour, "Silicon photonics," J. Lightw. Technol., vol. 24 no. 12 , pp. 4600-4615, Dec. 2006.

[75] W. Hoving, R. Heideman, D. Geuzebroek, A. Leinse, E. Klein, and R. Dekker, "Low loss, high contrast planar optical waveguides based on lowcost CMOS compatible LPCVD processing," in Proc. SPIE, vol. 6996, 2008, pp. 699612-1-699612-6.

[76] T. Komljenovic et al., "Heterogeneous silicon photonic integrated circuits," J. Lightw. Technol., vol. 34, no. 1, pp. 20-35, Jan. 2016.

[77] S. Chen et al., "Electrically pumped continuous-wave III-V quantum dot lasers on silicon," Nature Photon., vol. 10, no. 5, pp. 307-311, 2016.

[78] W. Bogaerts, M. Fiers, and P. Dumon, "Design challenges in silicon photonics,” J. Sel. Topics Quantum Electron., vol. 14, no. 4, pp. 1-8, 2014.

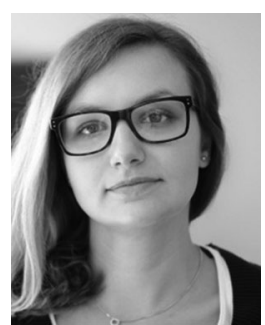

Katarzyna Bałakier received the M.Sc. degree in electronics and telecommunications with specialization in optoelectronics from Białystok University of Technology, Białystok, Poland, in 2006 and the Ph.D. degree in photonics from University College London, London, U.K., in 2016.

She worked as an Engineer for LG Electronics between 2006 and 2007. In 2007, she moved to Madrid, Spain, to join Sener Ingenieria y Sistemas, where she worked in the Aerospace Division on development of metrology and spectroscopy systems for space applications. In 2010, she was appointed as a Marie Curie Research Fellow with the Ultra-Fast Photonics Group, University College London, London, U.K., where she continues to work as a Research Associate since 2013. Her research interests include photonic integrated circuits for millimetre-wave and $\mathrm{THz}$ signals generation, microwave photonics, and laser's phase stabilization techniques.

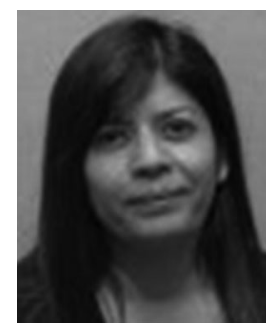

Lalitha Ponnampalam received the B.Eng. degree from University College London, London, U.K., in 1992, the M.S.E.E. degree from CREOL, University of Central Florida, Orlando, FL, USA, in 1998 , and the Ph.D. degree from University of Cambridge, Cambridge, U.K., in 2002. During her Ph.D. studies, she was engaged in research on the design of a novel tunable semiconductor laser. From 2001 to 2007, she was a Senior Scientist at Bookham Technology, U.K., which later became part of Oclaro, Inc. She was involved in the design and development of widely tunable semiconductor lasers and electroabsorption modulators. Since 2007, she has been with the Ultrafast Photonics Group, Department of Electronic and Electrical Engineering, University College London. Her current research interests include photonic integration, optical phase-lock loops, optical frequency comb generators, tunable laser diodes, and photonic generation of $\mathrm{THz}$ signals.

Dr. Ponnampalam is a member of the Institution of Engineering and Technology and a Chartered Engineer. 


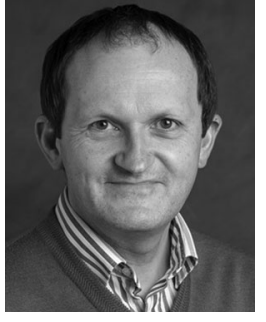

Martyn J. Fice (S'86-M'87) received the B.A. degree in electrical sciences and the Ph.D. degree in microelectronics from the University of Cambridge, Cambridge, U.K., in 1984 and 1989, respectively.

In 1989, he joined STC Technology Laboratories, Harlow, U.K. (later acquired by Nortel), where he was engaged for several years in the design and development of InP-based semiconductor lasers for undersea optical systems and other applications. Subsequent work at Nortel involved research into various aspects of optical communications systems and networks, including wavelength-division multiplexing, all-optical wavelength conversion, optical regeneration, and optical packet switching. In 2005, he joined the Photonics Group, Department of Electronic and Electrical Engineering, University College London, London, U.K., as a Senior Research Fellow. He is currently a Lecturer in the same department, with research interests in millimeter and $\mathrm{THz}$ wave generation and detection, optical phase locking, coherent optical detection, optical transmission systems, and photonic integration. He is a member of the Institution of Engineering and Technology and a Chartered Engineer.

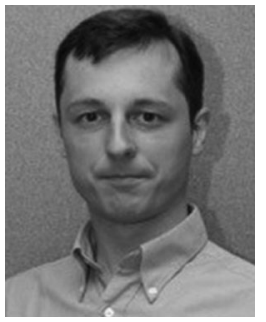

Cyril C. Renaud received the degree of engineering from the Ecole Supérieure d'Optique, Orsay, France, and the Diplôme d'Etudes Approfondies in optics and photonics from the University Paris XI, Orsay, France, in 1996. He spent one year as a Project Engineer with Sfim-ODS, working on the development of microchips lasers and portable range finders. He, then, joined the Optoelectronics Research Centre, University of Southampton, Southampton, U.K., in 1998, to work on diode-pumped high-power ytterbium-doped fibre-lasers, with particular interest on Q-switched system and 980-nm generation. This work led to the award of a Ph.D. in 2001. He is currently a Reader in Photonics at University College London, and the UCL Site Director for the UCL/Cambridge Doctoral Training Centre in Integrated Photonic and Electronic Systems. His work has led to more than 140 publications in peer-reviewed journals and international conferences, and three patents.

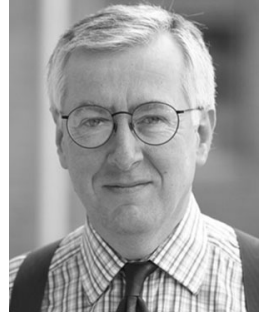

Alwyn J. Seeds (M'80-F'97) received the B.Sc., $\mathrm{Ph} . \mathrm{D}$., and D.Sc. degrees from the University of London, London, U.K. From 1980 to 1983, he was a Staff Member at Lincoln Laboratory, Massachusetts Institute of Technology, where he worked on GaAs monolithic millimeter-wave integrated circuits for use in phased-array radar. Following three years as a Lecturer in telecommunications at Queen Mary College, University of London he moved to University College London in 1986, where he is currently a Professor of Opto-Electronics and the Head of the Photonics Group. He has published more than 350 papers on microwave and optoelectronic devices and their systems applications. His current research interests include photonic integration, semiconductor optoelectronic devices, wireless and optical communication systems.

Prof. Seeds is a Fellow of the Royal Academy of Engineering (U.K.). He has been a Member of the Board of Governors and the Vice-President for Technical Affairs of the IEEE Photonics Society (USA). He has served on the programme committees for many international conferences. He is a co-founder of Zinwave, a manufacturer of wireless over fibre systems. He was awarded the Gabor Medal and Prize of the Institute of Physics in 2012. 